\title{
Natural Agents Used in Chemoprevention of Aerodigestive and GI Cancers
}

\author{
Jay Morris $^{1}$ • Yuan Fang ${ }^{1} \cdot$ Keya De Mukhopdhyay $^{1} \cdot$ Michael J. Wargovich $^{1}$
}

Published online: 16 January 2016

(C) Springer International Publishing AG 2016

\begin{abstract}
Aerodigestive cancers are on an increasing level in both occurrence and mortality. A major cause in many of these cancers is disruption of the inflammatory pathway, leading to increased cell proliferation and epigenetic silencing of normal regulatory genes. Here, we review the research on several natural products: silibinin, silymarin, quercetin, neem and nimbolide, gingerol, epigallatecatechin-3- gallate, curcumin, genistein, and resveratrol conducted on aerodigestive cancers. These types of cancers are primarily those from oral cavity, esophagus/windpipe, stomach, small and large intestine, colon/rectum, and bile/pancreas tissues. We report on the utilization in vivo and in vitro systems to research these dose effects on the inflammatory and epigenetic pathway components within the aerodigestive cancer. To follow up on the basic research, we will discuss the remaining research questions and future directions involving these natural products as putative stand alone or in combination with clinical agents.
\end{abstract}

Keywords Natural product - Quercetin · EGCG · Genistein · Resveratrol · Aerodigestive cancer

This article is part of the Topical Collection on Cancer Chemoprevention

Jay Morris

morrisj1@uthscsa.edu

1 Department of Molecular Medicine, The University of Texas Health Science Center at San Antonio, 7703 Floyd Curl Drive, STRF, MC 8257, San Antonio, TX 78229, USA

\section{Introduction}

Cancers of the upper aerodigestive tract constitute approximately $4 \%$ of all malignancies [1]. The combined organs and tissues of the respiratory tract and the upper part of the digestive tract (including the lips, mouth, tongue, nose, throat, vocal cords, and part of the esophagus and windpipe) are referred as aerodigestive tract. There are a number of factors that can increase a person's risk for developing cancers of the upper aerodigestive tract which includes smoking, moderate to heavy alcohol consumption, exposure to asbestos, and other toxic substances, genetic/family history, previous occurrence of upper aerodigestive cancer, pulmonary diseases, including chronic obstructive pulmonary disease (COPD), emphysema, chronic bronchitis, idiopathic pulmonary fibrosis, etc. (www. cancer.gov). Within the lower aerodigestive tract the, stomach, small intestine, colon, and rectum are the major tissue sites of deleterious effects [2-5], encompassing approximately $11 \%$ of all cancers.

One of the major corrupted components within aerodigestive cancers is the disruption of normal inflammatory signaling pathways. Pathways involved in JAK/STAT, MAPK, prostaglandin synthesis, and NF- $\mathrm{KB}$ signaling have all been implicated as therapeutic intervention strategies [6-17]. Diet and lifestyle are major contributing factors to increased cancer risk in these tissues $[18,19]$. Numerous studies show that dietary intake antioxidants and/or polyphenols have an inverse risk effect on several aerodigestive cancers by mitigating the increase in inflammation [20-24]. Curcumin, a compound from turmeric, along with several other natural agents, silibinin, silymarin, quercetin, neem and nimbolide, gingerol, epigallatecatechin-3-gallate (EGCG), genistein, and resveratrol, all have been heavily research in aerodigestive cancers as preventive agents, front line therapy and/or in combination with more traditional therapeutics agents in the clinic 
$[6,9,25-33]$. In this review, we will focus on these compounds, their effects on inflammatory signaling pathways, and effects on epigenetic regulators and discuss how these natural products (NPs) can enhance clinical treatments.

\section{Inflammatory Effectors}

\section{JAK/STAT Signaling}

The JAK/STAT is the principal signaling pathway including transcriptional factors responding to extracellular ligands, cytokines, and growth factors; it affects various cellular functions, such as metastasis, proliferation, growth, and immune response [34]. Upon activation, STAT family proteins translocate into the nucleus, where it dimerizes and binds specific regulatory sequences, activating downstream target genes, e.g.,cyclins D1/D2, Myc, Bcl-xL, and Mcl-1 [35]. Therefore, activation of JAK/STAT pathway plays important role in activating cell cycle and inhibiting apoptosis [36]. In recent publications, gastric [37], pancreatic [17], colon [16], rectal [38], and cancer cells were shown to express high levels of STAT proteins, which is interesting given the implications for blockage of JAK/STAT pathway to inhibit tumor progression.

A clinical study found that in the nucleus of 40 cancer cells in human gastric cancer specimens, 11 (27.5\%) showed activated form of STAT3, Tyr-705 phospho-stat3. Signal transduction and activator of transcription 3(STAT3) signaling is constitutively activated in various tumors and is involved in cell survival and proliferation during oncogenesis [15]. A number of studies have shown that the quercetin, the major constituent of the flavonol subclass of flavonoids, inhibits the expression of STAT3 with drug treatment at the dosage of $40 \mu \mathrm{mol} / \mathrm{L}$ for $48 \mathrm{~h}$, thereby resulting in the suppression of gastric cancer cell's growth [37]. In addition, dietary supplementation of quercetin attenuated the growth of orthotopically transplanted pancreatic xenografts [39]. Moreover, a study of Velázquez group showed that when $\mathrm{Apc}^{\mathrm{Min} /+}$ mice were treated with $25 \mathrm{mg} / \mathrm{kg}$ of quercetin daily for 3 weeks, tumor burden of these mice was attenuated compared with control groups [40॰]. Silibinin, the major biologically active compound of the milk thistle (Silybum marianum), has been reported to inhibit the migratory and invasive potential of human tongue squamous cell carcinoma cells in vitro [41] and human colorectal carcinoma (CRC) HT29 xenograft growth [42]. Clear mechanism of its chemoprevention effects on oral and CRC cancer was not shown, but Alpna Tyagi's study on lung cancer found that silibinin decreased phosphorylation STAT3 (ser727) $(16 \%, p<0.01)$ in lung cancer cells [42], suggesting that silibinin may block the constitutive and inducible activation of STAT3, resulting in reduction in expression of STAT3 target genes, such as JAK2, v-src, and cyclin D1. Many clinical studies have explored the effect of curcumin on colorectal and pancreatic cancer prevention or treatment and have reported no toxicity with moderate dose (440 and $2200 \mathrm{mg}$ /day) of curcumin over a few months [43-45]; phase II trial conducted by Dhillon et al. showed decreased phosphorylated signal transducer and activator of transcription 3 in peripheral blood mononuclear cells from patients [44].

\section{MAPK Pathway}

Mitogen-activated protein kinases (MAPK) are serine/ threonine (proXser/ThrPro) kinases, and they can convert various extracellular signals into intracellular responses through serial phosphorylation cascades [46]. When extracellular mitogen binds to extracellular signal-regulated kinase (ERK), it will activate GTPase (Ras) by converting its GDP to GTP, then phosphorylates downstream MAP3K (e.g., Raf), which in turn activates ERK, JNK, and p38 [47]. When all these MAPKs are activated, a lot of downstream transcription factors, such as c-myc, c-jun, activating transcription factor-2 (ATF2), GADD153, myocyte enhancer factor-2C (MEF2C), and Sin1-associated protein (SAP-1), will get phosphorylated, leading to a variety of cellular responses including inflammation, cell proliferation, differentiation, and migration [48, 49]. Several natural dietary phytochemicals have been found to inhibit MAPK pathway, suggesting their abilities to be chemoprevention therapy for cancer progression.

6-Gingerol, a major component of ginger (Zingiber officinale), incubated with human hepatoma Hep3B cells human pancreatic duct cell-derived cancer PANC-1 cells with concentration of $\geq 10 \mu \mathrm{M}$ downregulation of the extracellular signal-regulated kinase (ERK); thus, significantly reduced MAPK signaling [29, 50] Gingerol was also found to suppress PMA-induced I $\mathrm{K} \mathrm{B} \alpha$ degradation and translocation of $\mathrm{p} 65$ to nucleus in mouse skin by blocking of upstream kinase p38 MAPK [51]. Moreover, a recent study by Weng CJ et al. found that HepG2 and Hep3B cells with ginerol treatment $(\geq 10 \mu \mathrm{M}$ for $24 \mathrm{~h}$ ) showed MMP-9 suppression, TIMP-1 induction, and reduced invasion or metastasis [52].

Nimbolide, a component of neem (Azadirachta indica) inhibited phosphorylation of ERK1/2 of colon cancer cell lines (WiDr and HCT116) in a time-dependent manner with dosage of $1.25 \mu \mathrm{M}$. As a result, downstream MAPK proteins, including p38 and c-Jun amino-terminal kinases (JNK), are activated and correlated to the activation of ERKs [53]. This result might be able to explain the beneficial effect of Nimbolide on animal model of oral oncogenesis conducted by G. Harish Kumar research group [54]. Another phytochemical silibinin was found to inhibit SNU216 and SNU668 gastric cancer cell growth and migration by inhibiting phosphorylation of MER/ERK pathway [12]; silibinin also inhibits the growth of SW480 xenograft tumors carrying the mutant APC gene [55]. Resveratrol has also been shown to inhibit growth in human oral cancer cell line (SCC- 
9) in a dose-dependent manner by inhibiting phosphorylation of MAPK response element targets [56].

\section{AKT/PI3K Pathway}

The Akt/PI3K (phosphatidylinositol 3-kinase) pathway plays a very important role in the regulation of cell proliferation and survival. It can enhance cell survival by activating cell proliferation and inhibition of cell metastasis [13], and the dysregulation of a lot of components of the Akt/PI3K pathway has been found in many human cancers' cases [14]. PI3K can be activated by receptor tyrosine kinases when they are bound by a ligand, and the PI3K activation can activate AKT which activates mTOR and has a lot of downstream effects, like cell growth, cell renewal, and resistance to chemotherapy [30]. Therefore, it is important to explore the therapeutic target in this pathway, and it can become a promising target for therapy.

Recently, it has shown that quercetin can reduce tumor cell proliferation and the growth of orthotopically transplanted pancreatic xenografts was decreased when quercetin was used as dietary supplementation [10,39]. Park JH group reported that quercetin downregulated ErbB2/ErbB3 signaling and the Akt pathway, thus inducing apoptosis in SW480 and HT-29 colon cancer cell and inhibited cell growth in a dosedependent manner when cells were treated with 25,50 , or $100 \mu \mathrm{mol} / \mathrm{L}$ quercetin for $72 \mathrm{~h} \mathrm{[31]}$.

6-Gingerol treatment to in vitro neonatal rat cardiomyocytes and $\mathrm{H} 9 \mathrm{c} 2$ cell line suppresses doxorubicintriggered oxidative stress and apoptosis through activating PI3K/Akt pathway [6]-GR upregulated expression of PI3K and p-Akt in DOX-induced NRCs in a dose-dependent manner, and the optimal dose is $100 \mu \mathrm{M}$. Moreover, the cytoprotection of higenamine plus [6] gingerol could be abrogated by a PI3K inhibitor LY294002 [57]. All of the studies show that dietary agents target the PI3K/Akt signaling pathway to inhibit cell proliferation, highlighting a potential target for therapy of cancer.

\section{NF-KB Pathway}

The NF- $\mathrm{kB}$ family of transcription factors has an essential role in inflammation and innate immunity, and this has been increasingly recognized as a crucial player in many steps of cancer initiation and progression [58]. This NF- $\mathrm{KB}$ is a nuclear factor that binds to the enhancer element of the immunoglobulin kappa light chain of activated B cells [59]. The proteins harboring this specific DNA binding activity are expressed in almost all cell types and regulate many target genes with a variety of functions [11]. There are five members of this transcription factor family, p65 (RelA), RelB, c-Rel, NF-kB1, and $\mathrm{NF}-\mathrm{kB} 2$, of which NF-kB1 and NF-kB2 are synthesized as pro-forms (p105 and $\mathrm{p} 100$ ) and are proteolytically processed to $\mathrm{p} 50$ and $\mathrm{p} 52$, respectively [60]. In contrast to the other members of the NF- $\mathrm{KB}$ family, p50 and p52 do not contain a transactivation domain [61]. So dimers of $\mathrm{p} 50$ and $\mathrm{p} 52$, which bind to NF- $\mathrm{kB}$ elements of gene promoters, act as transcriptional repressors [62]. However, when p50 or p52 is bound to a member containing a transactivation domain, such as p 65 or RelB, they constitute a transcriptional activator [63]. The fact that different NF- $\mathrm{kB}$ dimers have differential preferences for variations of the DNA-binding sequence enhances the complexity of this transcriptional regulation system [64]. Thus, different target genes are differentially induced by distinct NF- $\mathrm{KB}$ dimers. Besides, the sites for phosphorylations and other post-translational modifications in the NF- $\mathrm{kB}$ subunits are important for activation and crosstalk with other signaling pathways [65]. NF- $\mathrm{KB}$ in the blood stream is usually bound to the inhibitory protein I $\mathrm{kB}$ which renders it inactive. However, during an inflammatory response, the IkB kinase phosphorylates the IKB protein, thus releasing NF- $\mathrm{KB}$. NF- $\mathrm{KB}$ activation then leads other inflammatory cytokines such as TNF- $\alpha$ and interleukin-1 (IL-1) to bind to their receptors and become activated [10].

Silymarin is a polyphenolic flavonoid derived from the fruits and seeds of the milk thistle, also called artichoke S. marianum, which has anti-inflammatory, cytoprotective, and anticarcinogenic effects. Silymarin may involve suppression of NF-KB, a nuclear transcription factor, which regulates the expression of various genes involved in inflammation, cytoprotection, and carcinogenesis, to produce these effects [9]. Another flavonoid, silibinin, has shown strong preventive and therapeutic efficacy in different pre-clinical models through various mechanisms in colorectal cancer [66]. Studies have shown that silibinin strongly inhibits TNF- $\alpha$-induced NF-KB activation in human CRC cells [67]. Silibinin treatment $(50-200 \mu \mathrm{M})$ of human CRC SW480, LoVo, and HT2 9 cells strongly inhibits tumor necrosis factor- $\alpha$-induced NF-KB activation together with decreased nuclear levels of both p65 and p50 sub-units. Silibinin also significantly increased I $\mathrm{k} \alpha$ level with a concomitant decrease in phospho$\mathrm{I} \kappa \mathrm{B} \alpha$, without any effect on TNFR1, TRADD, and RIP2, indicating its inhibitory effect on $\operatorname{I\kappa } B \alpha$ kinase $\alpha$ activity [67]. In the same study, the effect of oral silibinin feeding on NF-kB pathway in SW480 (cycloxygenase (COX) COX-2 negative) and LoVo (COX-2 positive) tumor xenografts in nude mice were determined. Together with its inhibitory efficacy on tumor growth and progression, silibinin inhibited NF-KB activation in both xenografts [67].

Quercetin, a flavonol, is the most common flavonoid in nature and is often linked to sugars such as rutin (quercetin3-rutinoside) and quercitrin (quercetin-3-rhamnoside) [68]. Quercetin is reported to have antioxidant properties [28] associated with antithrombotic, antihypertensive, anticarcinogenic, and anti-inflammatory effects [69]. Quercetin downregulates Bcl-2 through inhibition of NF-KB [70]. Clinical trials of quercetin effect on $\mathrm{CRC}$ are lacking and evidence 
of efficacy of quercetin comes from preclinical studies. Thus, further research in this field is needed.

Resveratrol is a polyphenol derived from grapes, berries, and other plant sources. It is a natural compound that aids in suppressing the risk of obesity-induced cancer. Resveratrol has a role in suppressing inflammatory responses through decreasing nitric oxide levels and inhibiting the phosphorylation of the IKB complex, thus interfering with the activation of NF-kB-dependent mechanisms [71]. Resveratrol suppresses the activity of NFkB by interfering its DNA-binding ability. Resveratrol at doses of 0.5 or $1.0 \mathrm{~g}$ reduced CRC tumor cell proliferation by $5 \%(p=0.005)$ and are enough to induce anticarcinogenic effects in colon tumors [72].

A. indica (neem) containing various bioactive components is a promising candidate for chemoprevention. Studies have shown that neem leaf extract acts on different levels of the NF-KB pathway, and it induced apoptosis in colorectal cancer cells [27]. Several groups reported anticancer, anti-inflammatory, and antioxidant activities of neem tree extracts without providing in-depth analysis of the molecular mechanisms leading to NLE-induced inhibition of NF-kB activation. Phytochemicals such as nimbolide, derived from Neem, can target multiple steps along the NF-KB signaling circuit are promising candidates for future phytochemical-based mechanistic pathway-targeted anticancer regimens [73]. One study has shown that Nimbolide inhibits the NF-KB activation pathway induced in carcinogenesis through direct interaction with Cys ${ }^{179}$ of IKK- $\beta$, leading to suppression of IKB $\alpha$ phosphorylation and degradation, inhibition of p65 nuclear translocation, downregulation of NF-kB-regulated gene products, inhibition of cell proliferation, and potentiation of apoptosis induced by TNF- $\alpha$ and chemotherapeutics in oral squamous tumor cells [74].

Gingerol is the chief phenolic compound from ginger, a spice of Southeast Asia, with antioxidant, anti-inflammatory, and anti-tumor properties. Gingerol suppresses inflammation by blocking the movement of NF-kB into the nucleus, with the resulting downregulation of such inflammatory cytokines as TNF- $\alpha$, as well as inducible nitric oxide synthase (iNOS). Pretreatment with [6] gingerol resulted in a decrease in both TPA-induced DNA binding and transcriptional activities of NF- $\kappa B$ through suppression of I $\mathrm{K} B \alpha$ degradation and $\mathrm{p} 65$ nuclear translocation. Phosphorylation of both $\mathrm{I} \kappa \mathrm{B} \alpha$ and p65 was substantially blocked by [6] gingerol. In addition [6], gingerol inhibited TPA-stimulated interaction of phospho-p65-(Ser-536) with cAMP response element binding protein-binding protein, a transcriptional coactivator of $\mathrm{NF}-\mathrm{kB}[8]$.

\section{Cyclooxygenase Pathway}

Cyclooxygenase (COX), also known as prostaglandin synthase, is the rate-limiting enzyme responsible for the conversion of arachidonic acid (AA) into the various prostaglandins (PGs), a family of lipid mediators that have widespread and diverse biological functions [75]. There are two isoforms of COX, with distinct tissue distributions and physiological functions. COX-1 is constitutively expressed in many tissues and cell types, whereas the inducible isoenzyme COX-2 is pro-inflammatory in nature and expressed only in response to certain stimuli such as mitogens, cytokines, and growth factors. COX-2 is upregulated in a number of epithelial cancers, including in upper aerodigestive tract (UADT) premalignant and malignant lesions [7].

Curcumin is a phytochemical derived from the spice turmeric and has a potential in decreasing inflammation and inhibiting the growth of neoplastic cells through cell cycle arrest and promoting apoptosis by activating the mitochondria-mediated pathway. Curcumin has a role in anti-inflammation where it targets and inhibits COX-2 gene expression, nitric oxide synthase, NF- $\mathrm{KB}$, and $\mathrm{PGE}_{2}[26,76]$. In a phase IIa clinical trial, curcumin at a dose of 2 or $4 \mathrm{~g}$ was administered over a 30 -day period to 44 eligible smokers with 8 or more ACF. Results showed that curcumin at a dose of $4 \mathrm{~g}$ significantly reduced the ACF number by $40 \%(p<0.005)$ whereas the ACF number was not reduced by the $2 \mathrm{~g}$ dose [77•]. It has been shown that curcumin enhances the effect of chemotherapy against colorectal cancer cells by inhibition of NF-KB and Src protein kinase signaling pathways [25]. Curcumin has a role in anti-inflammation where it targets and inhibits COX-2 gene expression. In a study, the combined effects of hexahydrocurcumin (HHC) with 5-FU exhibit a synergistic inhibition by decreasing ACF formation mediated by downregulation of COX-2 expression [78].

Clinical trials of COX-2 inhibitors have shown that inhibition of this enzyme can prevent the formation of colonic adenomas and potentially carcinomas; however, concerns regarding the potential toxicity of these drugs have limited their use as a chemopreventive strategy. Curcumin, resveratrol, and quercetin are three chemopreventive agents that are able to suppress multiple signaling pathways involved in carcinogenesis including COX and, hence, are attractive candidates for possible clinical intervention research.

Resveratrol (RSVL; 3,5,4'-trihydroxy-trans-stilbene) demonstrates nonselective COX-2 inhibition. We report herein that RSVL directly binds with COX-2, and this binding is absolutely required for RSVL's inhibition of the ability of human colon adenocarcinoma HT-29 cells to form colonies in soft agar. It has been shown that RSVL inhibited COX-2mediated PGE(2) production in vitro and ex vivo. HT-29 human colon adenocarcinoma cells expressing high levels of COX-2 and RSVL showed suppressed anchorageindependent growth of these cells in soft agar. RSVL suppressed growth of COX-2(+/+) cells by 60 to $80 \%$, respectively. Notably, cells deficient in COX-2 were unresponsive to RSVL or RSVL-2 [6]. 
It has been shown that [6]-gingerol inhibits TPA-induced COX-2 expression in vivo by blocking the p38 MAP kinaseNF-kB signaling pathway [8]. In another study, 6-gingerol effectively suppressed tumor growth in vivo in nude mice [79]. Specifically, in CRC, [6]-gingerol has been shown to reduce the incidence of CRCs in a rat azoxymethane (AOM) model [80] and to inhibit CRC cell proliferation and endothelial cell tube formation [81]. While we have focused on a few pathways within aerodigestive cancers (Table 1), these compounds have shown to have effects in other cancer types and tumorigenic pathways.

\section{Epigenetic Effectors}

Genetic mutations have long been a central theme in the causality of cancer. Recently, Hanahan and Weinberg [82] expanded their previous tenets on the origins of human cancer to now include epigenetic events in the pathway of carcinogenesis. Across the paradigm of cancer, recent data suggest that epigenetic events are of central importance in regulation of tumor formation and progression, possibly creating a new avenue for prevention and treatment [82-84]. There are many intrinsic and extrinsic factors that encompass epigenetic changes, and these can involve diet, heritability, and the environment. Regulation of the epigenome is under the control of DNA methyltransferases (DNMTs), histone deacetylases (HDACs), histone acetyltransferases (HATs), and associated modifier proteins $[83,85,86]$. Compounds regulating these proteins or altering their function is an emerging field for drug development. Some pharmacologic inhibitors such as 5-Aza2'-deoxycytidine (5aza-dc) and suberoylanilide hydroxamic acid (SAHA) have entered clinical testing, but off-target toxicity has limited its progress [87].

Targeting epigenetic regulators is a new paradigm for cancer prevention [87-90]. Within this field, NPs such as resveratrol (from grapes), genistein (from soy), and sulforaphane (broccoli) are reported to modulate cancer risk while modifying epigenetic pathways [88, 91-93]. One extensively studied NP is epigallocatechin gallate (EGCG), the major polyphenolic compound from green tea $[89,94,95 \bullet$, 96-100]. In methylation-sensitive human colon cancer cells, EGCG at $100 \mu$ has been shown to decrease DNMT3a protein levels and increased DNMT3a protein degradation [101]. Sulforaphane, on the other hand, had little effect on DNMT transcripts levels in human colon cancer cells [102]. In terms of aerodigestive cancers, little research outside of in vitro cell studies has been conducted using these NPs. This dearth of information suggests an open avenue for future basic research to possibly advance these compounds towards clinical testing.

HDACs decrease the open conformation of DNA shutting down gene transcription, and their increased activity has been implicated in numerous cancers [103]. EGCG at $100 \mu \mathrm{M}$ decreased HDAC3 protein levels in HCT116 colon cancer cells and in combination (EGCG $10 \mu \mathrm{M}$ ) with sodium butyrate decreased HDAC1 activity in both HT29 and HCT116 colon cancer cells [101, 104]. In pancreatic cancer cell line AsPC-1, ECGC treatment can disrupt invasive metastatic by perturbing epigenetic modification of Snail 1 expression, thus shutting off the downstream target activation [105]. In HT29 colon cancer cell line, both EGCG and genistein decreased HDAC1 protein levels [106]. EGCG $(20 \mu \mathrm{M})$ with sulforaphane $(25 \mu \mathrm{M})$ treatment of HT29 human colon cancer cells decreased cell viability, suggesting a synergistic effects of multiple NP treatment in cancer cells [107•]. With the expansion of epigenetic research tools, further basic research in aerodigestive cancers using NP as individual or in combination therapies will allow better understanding of their future role as clinical agents.

\section{Questions to Answer and Future Directions}

These natural constituents tend have less aggressive side effects than standard clinical therapies and present another or additional avenue of cancer prevention/treatment [108-113].

Table 1 Natural product and aerodigestive cancer targets

\begin{tabular}{|c|c|c|c|c|}
\hline Natural product & Colo/Rectal & Gastric & Pancreas & Oral \\
\hline Silymarin & $\downarrow N F k B$ & & & \\
\hline Quercetin & $\downarrow \mathrm{APC} /{ }^{\mathrm{min}+}$ tumors, & STAT3 & $\downarrow$ Xenograft tumors, $\downarrow$ ErbB2/B3 & \\
\hline Silibinin & $\downarrow$ cell migration & $\downarrow$ ERK phosphorylation & & $\downarrow$ cell migration \\
\hline Curcumin & $\downarrow \mathrm{NFkB}, \downarrow \mathrm{COX} 2$ & & & \\
\hline Gingerol & $\downarrow \mathrm{NFkB}, \downarrow$ MAPK & & $\downarrow$ ERK phosphorylation & \\
\hline Nimbolide/neem & $\downarrow$ ERK1/2 phosphorylation & & & $\downarrow N F k B$ \\
\hline Resveratrol & $\downarrow N F k B$ & & & $\downarrow$ MAPK phosphorylation \\
\hline EGCG & $\downarrow$ DNMT3a, HDAC1, HDAC3 & & $\downarrow$ Snail 1 & \\
\hline Genistein & $\downarrow$ HDAC1 & & & \\
\hline
\end{tabular}


However, several questions remain: (1) Is dietary consumption of the foods containing these or a supplement with the isolated single compound a better strategy? (2) Will limited in vitro research suggest that bioavailability of these compounds might limit their effectiveness before they even research preliminary human trials? (3) Will research be better focused using these compounds in combination with conventional therapies instead of development as standalone therapeutic agents?

Epidemiological data suggests that green tea consumption can reduce CRC despite conflicting evidence that circulating serum levels of the tea constituents is much lower than those reported in the in vitro studies, and concentrations of active agents may be magnitude less in serum compared with cell line studies [114-124]. Several options are currently under exploration. Coadministration with other polyphenols enhances cellular absorption [125-127]. Piperine has been shown to enhance the anticancer effects of curcumin, cocoa flavanols enhance quercetin uptake by Caco-2 cells, and nanoparticle encapsulation has been shown to increase absorbed Np levels [125-127]. This enhancement is not without concern. When EGCG and genistein are given to mice, EGCG concentration were increased $50 \%$; however, when the EGCG was placed in the drinking water during the co-administration with genistein (contained in the diet), an increase in tumorigenesis occurred [128]. This type of research using combinations, delivery methods, and in vitro models highlights just how many unanswered questions remain.

\section{Conclusion}

All these issues aside, the use of NP as preventive or therapeutic agents still has a promising future in cancer chemotherapy. Lifestyle changes are one of the most readily adaptable factors one can implement to improve health. Dietary changes to increase bioactive dietary compounds can be a defense against chronic diseases, such as cancer. These compounds have the ability to alter numerous pro-cancer pathways to either slow down or halt tumor progression. Given the high cost and high toxic side effects of conventional therapies, the addition of NP into the treatment regime could have multiple benefits from cost reduction to enhanced efficacy of drugs and/or lower treatment dose. The ability to deliver these compounds in countless ways, their relatively safe side effects, and co-treatment flexibility with current standard therapies gives reason to continue exploration with these relevant NPs as therapeutics in future management strategies.

\section{Compliance with Ethical Standards}

Conflict of Interest Jay Morris, Yuan Fang, Keya De Mukhopdhyay, and Michael J. Wargovich declare that they have no conflict of interest.

Human and Animal Rights and Informed Consent This article does not contain any studies with human or animal subjects performed by any of the authors.

\section{References}

Papers of particular interest, published recently, have been highlighted as:

- Of importance

•- Of major importance

1. Muir C, Weiland L. Upper aerodigestive tract cancers. Cancer. 1995;75(1 Suppl):147-53.

2. Tarraga Lopez PJ, Albero JS, Rodriguez-Montes JA. Primary and secondary prevention of colorectal cancer. Clin Med Insights Gastroenterol. 2014;7:33-46. doi:10.4137/CGast.S14039.

3. Dubois RN. Role of inflammation and inflammatory mediators in colorectal cancer. Trans Am Clin Climatol Assoc. 2014;125:358 72. discussion 372-353.

4. Akiyama J, Alexandre L, Baruah A, Buttar N, Chandra R, Clark $\mathrm{AB}$, et al. Strategy for prevention of cancers of the esophagus. Ann N Y Acad Sci. 2014;1325:108-26. doi:10.1111/nyas.12529.

5. Xie Z, Qu Y, Leng Y, Sun W, Ma S, Wei J, et al. Human colon carcinogenesis is associated with increased interleukin-17-driven inflammatory responses. Drug Des Devel Ther. 2015;9:1679-89. doi:10.2147/DDDT.S79431.

6. Zykova TA, Zhu F, Zhai X, Ma WY, Ermakova SP, Lee KW, et al. Resveratrol directly targets COX-2 to inhibit carcinogenesis. Mol Carcinog. 2008;47(10):797-805. doi:10.1002/mc.20437.

7. Mohan S, Epstein JB. Carcinogenesis and cyclooxygenase: the potential role of COX-2 inhibition in upper aerodigestive tract cancer. Oral Oncol. 2003;39(6):537-46.

8. Kim SO, Kundu JK, Shin YK, Park JH, Cho MH, Kim TY, et al. [6]-Gingerol inhibits COX-2 expression by blocking the activation of p38 MAP kinase and NF-kappaB in phorbol esterstimulated mouse skin. Oncogene. 2005;24(15):2558-67. doi:10. 1038/sj.onc. 1208446.

9. Manna SK, Mukhopadhyay A, Van NT, Aggarwal BB. Silymarin suppresses TNF-induced activation of NF-kappa B, c-Jun N-terminal kinase, and apoptosis. J Immunol. 1999;163(12):6800-9.

10. Poligone B, Baldwin AS. Positive and negative regulation of NFkappaB by COX-2: roles of different prostaglandins. J Biol Chem. 2001;276(42):38658-64. doi:10.1074/jbc.M106599200.

11. May MJ, Ghosh S. Signal transduction through NF-kappa B. Immunol Today. 1998;19(2):80-8.

12. Kim S, Choi MG, Lee HS, Lee SK, Kim SH, Kim WW, et al. Silibinin suppresses TNF-alpha-induced MMP-9 expression in gastric cancer cells through inhibition of the MAPK pathway. Molecules. 2009;14(11):4300-11. doi:10.3390/ molecules 14114300 .

13. Leleu X, Jia X, Runnels J, Ngo HT, Moreau AS, Farag M, et al. The Akt pathway regulates survival and homing in Waldenstrom macroglobulinemia. Blood. 2007;110(13):4417-26. doi:10.1182/ blood-2007-05-092098. 
14. Vivanco I, Sawyers CL. The phosphatidylinositol 3-Kinase AKT pathway in human cancer. Nat Rev Cancer. 2002;2(7):489-501. doi:10.1038/nrc839.

15. Kanda N, Seno H, Konda Y, Marusawa H, Kanai M, Nakajima T, et al. STAT3 is constitutively activated and supports cell survival in association with survivin expression in gastric cancer cells. Oncogene. 2004;23(28):4921-9. doi:10.1038/sj.onc. 1207606.

16. Slattery ML, Lundgreen A, Kadlubar SA, Bondurant KL, Wolff RK. JAK/STAT/SOCS-signaling pathway and colon and rectal cancer. Mol Carcinog. 2013;52(2):155-66. doi:10.1002/mc. 21841.

17. Masamune A, Satoh M, Kikuta K, Suzuki N, Shimosegawa T. Activation of JAK-STAT pathway is required for platelet-derived growth factor-induced proliferation of pancreatic stellate cells. World J Gastroenterol. 2005;11(22):3385-91.

18. Yoon SL, Grundmann O, Williams JJ, Carriere G. Novel intervention with acupuncture for anorexia and cachexia in patients with gastrointestinal tract cancers: a feasibility study. Oncol Nurs Forum. 2015;42(2):E102-9. doi:10.1188/15.ONF.E102-E109.

19. Crosara Teixeira M, Braghiroli MI, Sabbaga J, Hoff PM. Primary prevention of colorectal cancer: myth or reality? World J Gastroenterol. 2014;20(41):15060-9. doi:10.3748/wjg.v20.i41. 15060.

20. Lin Y, Yngve A, Lagergren J, Lu Y. A dietary pattern rich in lignans, quercetin and resveratrol decreases the risk of oesophageal cancer. Br J Nutr. 2014;112(12):2002-9. doi:10.1017/ S0007114514003055.

21. Li Y, Go VL, Sarkar FH. The role of nutraceuticals in pancreatic cancer prevention and therapy: targeting cellular signaling, MicroRNAs, and epigenome. Pancreas. 2015;44(1):1-10. doi: 10.1097/MPA.0000000000000257.

22. Dawsey SM, Fagundes RB, Jacobson BC, Kresty LA, Mallery SR, Paski S, et al. Diet and esophageal disease. Ann N Y Acad Sci. 2014;1325:127-37. doi:10.1111/nyas.12528.

23. Boffetta P, Thies F, Kris-Etherton P. Epidemiological studies of oats consumption and risk of cancer and overall mortality. Br J Nutr. 2014;112 Suppl 2:S14-8. doi:10.1017/ S0007114514002268.

24. Mehta M, Shike M. Diet and physical activity in the prevention of colorectal cancer. J Natl Compr Cancer Netw. 2014;12(12):17216.

25. Shakibaei M, Mobasheri A, Lueders C, Busch F, Shayan P, Goel A. Curcumin enhances the effect of chemotherapy against colorectal cancer cells by inhibition of NF-kappaB and Src protein kinase signaling pathways. PLoS One. 2013;8(2), e57218. doi: 10.1371/journal.pone.0057218.

26. Sandur SK, Deorukhkar A, Pandey MK, Pabon AM, Shentu S, Guha S, et al. Curcumin modulates the radiosensitivity of colorectal cancer cells by suppressing constitutive and inducible NFkappaB activity. Int J Radiat Oncol Biol Phys. 2009;75(2):534 42. doi:10.1016/j.jijrobp.2009.06.034.

27. Hao F, Kumar S, Yadav N, Chandra D. Neem components as potential agents for cancer prevention and treatment. Biochim Biophys Acta. 2014;1846(1):247-57. doi:10.1016/j.bbcan.2014. 07.002.

28. Robak J, Gryglewski RJ. Flavonoids are scavengers of superoxide anions. Biochem Pharmacol. 1988;37(5):837-41.

29. Kim SO, Kim MR. [6]-gingerol prevents disassembly of cell junctions and activities of MMPs in invasive human pancreas cancer cells through ERK/NF- kappa B/snail signal transduction pathway. Evid Based Complement Alternat Med. 2013; 2013: 761852. doi:10.1155/2013/761852.

30. Subramaniam D, Ponnurangam S, Ramamoorthy P, Standing D, Battafarano RJ, Anant S, et al. Curcumin induces cell death in esophageal cancer cells through modulating Notch signaling.
PLoS One. 2012;7(2), e30590. doi:10.1371/journal.pone. 0030590 .

31. Kim WK, Bang MH, Kim ES, Kang NE, Jung KC, Cho HJ, et al. Quercetin decreases the expression of ErbB2 and ErbB3 proteins in HT-29 human colon cancer cells. J Nutr Biochem. 2005;16(3): 155-62. doi:10.1016/j.jnutbio.2004.10.010.

32. Cheng KC, Asakawa A, Li YX, Chung HH, Amitani H, Ueki T, et al. Silymarin induces insulin resistance through an increase of phosphatase and tensin homolog in Wistar rats. PLoS One. 2014;9(1), e84550. doi:10.1371/journal.pone.0084550.

33. Gharagozloo M, Javid EN, Rezaei A, Mousavizadeh K. Silymarin inhibits cell cycle progression and mTOR activity in activated human T cells: therapeutic implications for autoimmune diseases. Basic Clin Pharmacol Toxicol. 2013;112(4):251-6. doi:10.1111/ bcpt.12032.

34. Mohr A, Chatain N, Domoszlai T, Rinis N, Sommerauer M, Vogt $\mathrm{M}$, et al. Dynamics and non-canonical aspects of JAK/STAT signalling. Eur J Cell Biol. 2012;91(6-7):524-32. doi:10.1016/j.ejcb. 2011.09.005.

35. Kiger AA, Jones DL, Schulz C, Rogers MB, Fuller MT. Stem cell self-renewal specified by JAK-STAT activation in response to a support cell cue. Science. 2001;294(5551):2542-5. doi:10.1126/ science. 1066707.

36. Sengupta TK, Schmitt EM, Ivashkiv LB. Inhibition of cytokines and JAK-STAT activation by distinct signaling pathways. Proc Natl Acad Sci U S A. 1996;93(18):9499-504.

37. Qin Y, He LY, Chen Y, Wang WY, Zhao XH, Wu MY. Quercetin affects leptin and its receptor in human gastric cancer MGC-803 cells and JAK-STAT pathway. Xi Bao Yu Fen Zi Mian Yi Xue Za Zhi. 2012;28(1):12-6.

38. Slattery ML, Herrick JS, Lundgreen A, Wolff RK. Genetic variation in the TGF-beta signaling pathway and colon and rectal cancer risk. Cancer Epidemiol Biomarkers Prev. 2011;20(1):57-69. doi:10.1158/1055-9965.EPI-10-0843.

39. Angst E, Park JL, Moro A, Lu QY, Lu X, Li G, et al. The flavonoid quercetin inhibits pancreatic cancer growth in vitro and in vivo. Pancreas. 2013;42(2):223-9. doi:10.1097/MPA. 0b013e318264ccae.

40. Velazquez KT, Enos RT, Narsale AA, Puppa MJ, Davis JM, Murphy EA, et al. Quercetin supplementation attenuates the progression of cancer cachexia in Apc ${ }^{\mathrm{Min} /+}$ mice. J Nutr. 2014;144(6): 868-75. doi:10.3945/jn.113.188367. This article highlights the ability of a natural product (quercetin) to decrease inflammatory signals in cancer susceptible mouse models. The preventive strategy utilized also shows further benefits by decreasing the effects secondary maladies associated with some cancers.

41. Chen PN, Hsieh YS, Chiang CL, Chiou HL, Yang SF, Chu SC. Silibinin inhibits invasion of oral cancer cells by suppressing the MAPK pathway. J Dent Res. 2006;85(3):220-5.

42. Tyagi A, Singh RP, Ramasamy K, Raina K, Redente EF, DwyerNield LD, et al. Growth inhibition and regression of lung tumors by silibinin: modulation of angiogenesis by macrophageassociated cytokines and nuclear factor-kappaB and signal transducers and activators of transcription 3. Cancer Prev Res (Phila). 2009;2(1):74-83. doi:10.1158/1940-6207.CAPR-08-0095.

43. Kanai M, Yoshimura K, Asada M, Imaizumi A, Suzuki C, Matsumoto S, et al. A phase I/II study of gemcitabine-based chemotherapy plus curcumin for patients with gemcitabine-resistant pancreatic cancer. Cancer Chemother Pharmacol. 2011;68(1): 157-64. doi:10.1007/s00280-010-1470-2.

44. Dhillon N, Aggarwal BB, Newman RA, Wolff RA, Kunnumakkara AB, Abbruzzese JL, et al. Phase II trial of curcumin in patients with advanced pancreatic cancer. Clin Cancer Res. 2008;14(14):4491-9. doi:10.1158/1078-0432. CCR-08-0024. 
45. Sharma RA, McLelland HR, Hill KA, Ireson CR, Euden SA, Manson MM, et al. Pharmacodynamic and pharmacokinetic study of oral Curcuma extract in patients with colorectal cancer. Clin Cancer Res. 2001;7(7):1894-900.

46. Cobb MH, Goldsmith EJ. How MAP kinases are regulated. J Biol Chem. 1995;270(25):14843-6.

47. Downward J. Targeting RAS signalling pathways in cancer therapy. Nat Rev Cancer. 2003;3(1):11-22. doi:10.1038/nrc969.

48. Munshi A, Ramesh R. Mitogen-activated protein kinases and their role in radiation response. Genes Cancer. 2013;4(9-10):401-8. doi:10.1177/1947601913485414.

49. Min L, He B, Hui L. Mitogen-activated protein kinases in hepatocellular carcinoma development. Semin Cancer Biol. 2011;21(1):10-20. doi:10.1016/j.semcancer.2010.10.011.

50. Weng CJ, Chou CP, Ho CT, Yen GC. Molecular mechanism inhibiting human hepatocarcinoma cell invasion by 6-shogaol and 6-gingerol. Mol Nutr Food Res. 2012;56(8):1304-14. doi: $10.1002 / \mathrm{mnfr} .201200173$.

51. Aggarwal BB, Kunnumakkara AB, Harikumar KB, Tharakan ST, Sung B, Anand P. Potential of spice-derived phytochemicals for cancer prevention. Planta Med. 2008;74(13):1560-9. doi:10. 1055/s-2008-1074578.

52. Weng CJ, Wu CF, Huang HW, Ho CT, Yen GC. Anti-invasion effects of 6-shogaol and 6-gingerol, two active components in ginger, on human hepatocarcinoma cells. Mol Nutr Food Res. 2010;54(11):1618-27. doi:10.1002/mnfr.201000108.

53. Babykutty S, Priya PS, Nandini RJ, Kumar MA, Nair MS, Srinivas $\mathrm{P}$, et al. Nimbolide retards tumor cell migration, invasion, and angiogenesis by downregulating MMP-2/9 expression via inhibiting ERK1/2 and reducing DNA-binding activity of NFkappaB in colon cancer cells. Mol Carcinog. 2012;51(6):47590. doi:10.1002/mc.20812.

54. Harish Kumar G, Vidya Priyadarsini R, Vinothini G, Vidjaya Letchoumy P, Nagini S. The neem limonoids azadirachtin and nimbolide inhibit cell proliferation and induce apoptosis in an animal model of oral oncogenesis. Investig New Drugs. 2010;28(4):392-401. doi:10.1007/s10637-009-9263-3.

55. Kaur M, Velmurugan B, Tyagi A, Agarwal C, Singh RP, Agarwal R. Silibinin suppresses growth of human colorectal carcinoma SW480 cells in culture and xenograft through down-regulation of beta-catenin-dependent signaling. Neoplasia. 2010;12(5):41524.

56. Lin FY, Hsieh YH, Yang SF, Chen CT, Tang CH, Chou MY, et al. Resveratrol suppresses TPA-induced matrix metalloproteinase-9 expression through the inhibition of MAPK pathways in oral cancer cells. J Oral Pathol Med. 2014. doi:10.1111/jop.12288.

57. Chen YL, Zhuang XD, Xu ZW, Lu LH, Guo HL, Wu WK, et al. Higenamine combined with [6]-gingerol suppresses doxorubicintriggered oxidative stress and apoptosis in cardiomyocytes via upregulation of PI3K/Akt pathway. Evid Based Complement Alternat Med. 2013;2013:970490. doi:10.1155/2013/970490.

58. Hoesel B, Schmid JA. The complexity of NF-kappaB signaling in inflammation and cancer. Mol Cancer. 2013;12:86. doi:10.1186/ 1476-4598-12-86.

59. Sen R, Baltimore D. Multiple nuclear factors interact with the immunoglobulin enhancer sequences. Cell. 1986;46(5):705-16.

60. Caamano J, Hunter CA. NF-kappaB family of transcription factors: central regulators of innate and adaptive immune functions. Clin Microbiol Rev. 2002;15(3):414-29.

61. Marienfeld R, May MJ, Berberich I, Serfling E, Ghosh S, Neumann M. RelB forms transcriptionally inactive complexes with RelA/p65. J Biol Chem. 2003;278(22):19852-60. doi:10. 1074/jbc.M301945200.

62. Hayden MS, Ghosh S. NF-kappaB, the first quarter-century: remarkable progress and outstanding questions. Genes Dev. 2012;26(3):203-34. doi:10.1101/gad.183434.111.
63. Bours V, Franzoso G, Azarenko V, Park S, Kanno T, Brown K, et al. The oncoprotein Bcl-3 directly transactivates through kappa $\mathrm{B}$ motifs via association with DNA-binding p50B homodimers. Cell. 1993;72(5):729-39.

64. Wong D, Teixeira A, Oikonomopoulos S, Humburg P, Lone IN, Saliba D, et al. Extensive characterization of NF-kappaB binding uncovers non-canonical motifs and advances the interpretation of genetic functional traits. Genome Biol. 2011;12(7):R70. doi:10. 1186/gb-2011-12-7-r70.

65. Oeckinghaus A, Ghosh S. The NF-kappaB family of transcription factors and its regulation. Cold Spring Harb Perspect Biol. 2009;1(4):a000034. doi:10.1101/cshperspect.a000034.

66. Raina K, Agarwal R. Promise and potential of silibinin in colorectal cancer management: what patterns can be seen? Future Oncol. 2013;9(6):759-61. doi:10.2217/fon.13.51.

67. Raina K, Agarwal C, Agarwal R. Effect of silibinin in human colorectal cancer cells: targeting the activation of NF-kappaB signaling. Mol Carcinog. 2013;52(3):195-206. doi:10.1002/mc. 21843.

68. Williamson G, Manach C. Bioavailability and bioefficacy of polyphenols in humans. II. Review of 93 intervention studies. Am J Clin Nutr. 2005;81(1 Suppl):243S-55S.

69. Formica JV, Regelson W. Review of the biology of Quercetin and related bioflavonoids. Food Chem Toxicol. 1995;33(12):1061-80.

70. Priego S, Feddi F, Ferrer P, Mena S, Benlloch M, Ortega A, et al. Natural polyphenols facilitate elimination of HT-29 colorectal cancer xenografts by chemoradiotherapy: a Bcl-2- and superoxide dismutase 2-dependent mechanism. Mol Cancer Ther. 2008;7(10):3330-42. doi:10.1158/1535-7163.MCT-08-0363.

71. Panaro MA, Carofiglio V, Acquafredda A, Cavallo P, Cianciulli A. Anti-inflammatory effects of resveratrol occur via inhibition of lipopolysaccharide-induced NF-kappaB activation in Caco-2 and SW480 human colon cancer cells. Br J Nutr. 2012;108(9):162332. doi: $10.1017 / \mathrm{S} 0007114511007227$.

72. Patel KR, Brown VA, Jones DJ, Britton RG, Hemingway D, Miller AS, et al. Clinical pharmacology of resveratrol and its metabolites in colorectal cancer patients. Cancer Res. 2010;70(19): 7392-9. doi:10.1158/0008-5472.CAN-10-2027.

73. Kavitha K, Vidya Priyadarsini R, Anitha P, Ramalingam K, Sakthivel R, Purushothaman G, et al. Nimbolide, a neem limonoid abrogates canonical NF-kappaB and Wnt signaling to induce caspase-dependent apoptosis in human hepatocarcinoma (HepG2) cells. Eur J Pharmacol. 2012;681(1-3):6-14. doi:10. 1016/j.ejphar.2012.01.024.

74. Gupta SC, Prasad S, Reuter S, Kannappan R, Yadav VR, Ravindran J, et al. Modification of cysteine 179 of IkappaBalpha kinase by nimbolide leads to down-regulation of NF-kappaB-regulated cell survival and proliferative proteins and sensitization of tumor cells to chemotherapeutic agents. J Biol Chem. 2010;285(46):35406-17. doi:10.1074/jbc.M110.161984.

75. Smyth EM, Grosser T, Wang M, Yu Y, FitzGerald GA. Prostanoids in health and disease. J Lipid Res. 2009;50(Suppl): S423-8. doi:10.1194/jlr.R800094-JLR200.

76. Villegas I, Sanchez-Fidalgo S, de la Lastra CA. Chemopreventive effect of dietary curcumin on inflammation-induced colorectal carcinogenesis in mice. Mol Nutr Food Res. 2011;55(2):259-67. doi:10.1002/mnfr.201000225.

77. Carroll RE, Benya RV, Turgeon DK, Vareed S, Neuman M, Rodriguez L, et al. Phase IIa clinical trial of curcumin for the prevention of colorectal neoplasia. Cancer Prev Res (Phila). 2011;4(3):354-64. doi:10.1158/1940-6207.CAPR-10-0098. This paper shows that despite the issue of poor bioavailability with many natural products, utilizing curcumin supplementation in a phase IIa clinical trial reduced ACFs in one arm of the study. In addition it further builds on in vivo animal data and transitions the research into humans with similar results. 
78. Srimuangwong K, Tocharus C, Tocharus J, Suksamrarn A, Chintana PY. Effects of hexahydrocurcumin in combination with 5 -fluorouracil on dimethylhydrazine-induced colon cancer in rats. World J Gastroenterol. 2012;18(47):6951-9. doi:10.3748/wjg. v18.i47.6951.

79. Jeong CH, Bode AM, Pugliese A, Cho YY, Kim HG, Shim JH, et al. [6]-Gingerol suppresses colon cancer growth by targeting leukotriene A4 hydrolase. Cancer Res. 2009;69(13):5584-91. doi:10.1158/0008-5472.CAN-09-0491.

80. Yoshimi N, Wang A, Morishita Y, Tanaka T, Sugie S, Kawai K, et al. Modifying effects of fungal and herb metabolites on azoxymethane-induced intestinal carcinogenesis in rats. Jpn J Cancer Res. 1992;83(12):1273-8.

81. Brown AC, Shah C, Liu J, Pham JT, Zhang JG, Jadus MR. Ginger's (Zingiber officinale Roscoe) inhibition of rat colonic adenocarcinoma cells proliferation and angiogenesis in vitro. Phytother Res. 2009;23(5):640-5. doi:10.1002/ptr.2677.

82. Hanahan D, Weinberg RA. Hallmarks of cancer: the next generation. Cell. 2011;144(5):646-74. doi:10.1016/j.cell.2011.02.013.

83. Ferguson LR, Tatham AL, Lin Z, Denny WA. Epigenetic regulation of gene expression as an anticancer drug target. Curr Cancer Drug Targets. 2011;11(2):199-212.

84. Chik F, Szyf M, Rabbani SA. Role of epigenetics in cancer initiation and progression. Adv Exp Med Biol. 2011;720:91-104. doi: 10.1007/978-1-4614-0254-1_8.

85. Rajendran P, Ho E, Williams DE, Dashwood RH. Dietary phytochemicals, HDAC inhibition, and DNA damage/repair defects in cancer cells. Clin Epigenetics. 2011;3(1):4. doi:10.1186/18687083-3-4.

86. Miremadi A, Oestergaard MZ, Pharoah PD, Caldas C. Cancer genetics of epigenetic genes. Hum Mol Genet, $16 \mathrm{Spec}$ No 1. 2007;R28-49, doi:10.1093/hmg/ddm021.

87. Schnekenburger M, Diederich M. Epigenetics offer New horizons for colorectal cancer prevention. Curr Colorectal Cancer Rep. 2012;8(1):66-81. doi:10.1007/s11888-011-0116-z.

88. Vanden Berghe W. Epigenetic impact of dietary polyphenols in cancer chemoprevention: lifelong remodeling of our epigenomes. Pharmacol Res. 2012. doi:10.1016/j.phrs.2012.03.007.

89. Hardy TM, Tollefsbol TO. Epigenetic diet: impact on the epigenome and cancer. Epigenomics. 2011;3(4):503-18. doi:10.2217/ epi.11.71.

90. Huang J, Plass C, Gerhauser C. Cancer chemoprevention by targeting the epigenome. Curr Drug Targets. 2011;12(13):192556.

91. Papoutsis AJ, Borg JL, Selmin OI, Romagnolo DF. BRCA-1 promoter hypermethylation and silencing induced by the aromatic hydrocarbon receptor-ligand TCDD are prevented by resveratrol in MCF-7 Cells. J Nutr Biochem. 2011. doi:10.1016/j.jnutbio. 2011.08.001.

92. Tortorella SM, Royce SG, Licciardi PV, Karagiannis TC. Dietary sulforaphane in cancer chemoprevention: the role of epigenetic regulation and HDAC inhibition. Antioxid Redox Signal. 2014. doi:10.1089/ars.2014.6097.

93. Daniel M, Tollefsbol TO. Epigenetic linkage of aging, cancer and nutrition. J Exp Biol. 2015;218(Pt 1):59-70. doi:10.1242/jeb. 107110.

94. Suzuki Y, Miyoshi N, Isemura M. Health-promoting effects of green tea. Proc Jpn Acad Ser B Phys Biol Sci. 2012;88(3):88-101.

95.• Hardtner C, Multhoff G, Falk W, Radons J. (-)-Epigallocatechin-3gallate, a green tea-derived catechin, synergizes with celecoxib to inhibit IL-1-induced tumorigenic mediators by human pancreatic adenocarcinoma cells Colo357. Eur J Pharmacol. (2012). doi:10. 1016/j.ejphar.2012.03.039. The research presented here suggests one of the most beneficial traits natural products can offer to standard therapies - decreasing therapeutic doses without ameliorating efficacy. The combined effect of
EGCG with celecoxib suggests that the future of natural products in addition to preventive agents might be as combination strategies with standard therapies.

96. Volate SR, Muga SJ, Issa AY, Nitcheva D, Smith T, Wargovich MJ. Epigenetic modulation of the retinoid $X$ receptor alpha by green tea in the azoxymethane-APC ${ }^{\mathrm{Min} /}+\mathrm{H}$ mouse model of intestinal cancer. Mol Carcinog. 2009;48(10):920-33. doi:10.1002/mc. 20542.

97. Zhu Z, Wang Y, Liu Z, Wang F, Zhao Q. Inhibitory effects of epigallocatechin-3-gallate on cell proliferation and the expression of HIF-1alpha and P-gp in the human pancreatic carcinoma cell line PANC-1. Oncol Rep. 2012;27(5):1567-72. doi:10.3892/or. 2012.1697.

98. Wang H, Bian S, Yang CS. Green tea polyphenol EGCG suppresses lung cancer cell growth through upregulating miR-210 expression caused by stabilizing HIF-1alpha. Carcinogenesis. 2011;32(12):1881-9. doi:10.1093/carcin/bgr218.

99. Zhu BH, He YL, Zhan WH, Cai SR, Wang Z, Zhang CH, et al. (-)Epigallocatechin-3-gallate reduces vascular endothelial growth factor expression in gastric cancer cells via suppressing activity. Zhonghua Wei Chang Wai Ke Za Zhi. 2011;14(8):631-5.

100. Singh BN, Shankar S, Srivastava RK. Green tea catechin, epigallocatechin-3-gallate (EGCG): mechanisms, perspectives and clinical applications. Biochem Pharmacol. 2011;82(12): 1807-21. doi:10.1016/j.bcp.2011.07.093.

101. Moseley VR, Morris J, Knackstedt RW, Wargovich MJ. Green tea polyphenol epigallocatechin 3-gallate, contributes to the degradation of DNMT3A and HDAC3 in HCT 116 human colon cancer cells. Anticancer Res. 2013;33(12):5325-33.

102. Barrera LN, Johnson IT, Bao Y, Cassidy A, Belshaw NJ. Colorectal cancer cells Caco-2 and HCT116 resist epigenetic effects of isothiocyanates and selenium in vitro. Eur $\mathrm{J}$ Nutr. 2013;52(4):1327-41. doi:10.1007/s00394-012-0442-1.

103. Ellis L, Atadja PW, Johnstone RW. Epigenetics in cancer: targeting chromatin modifications. Mol Cancer Ther. 2009;8(6): 1409-20. doi:10.1158/1535-7163.MCT-08-0860.

104. Saldanha SN, Kala R, Tollefsbol TO. Molecular mechanisms for inhibition of colon cancer cells by combined epigeneticmodulating epigallocatechin gallate and sodium butyrate. Exp Cell Res. 2014;324(1):40-53. doi:10.1016/j.yexcr.2014.01.024.

105. Kim SO, Kim MR. (-)-Epigallocatechin 3-gallate inhibits invasion by inducing the expression of Raf kinase inhibitor protein in AsPC1 human pancreatic adenocarcinoma cells through the modulation of histone deacetylase activity. Int J Oncol. 2013;42(1): 349-58. doi:10.3892/ijo.2012.1686.

106. Groh IA, Chen C, Luske C, Cartus AT, Esselen M. Plant polyphenols and oxidative metabolites of the herbal alkenylbenzene methyleugenol suppress histone deacetylase activity in human colon carcinoma cells. J Nutr Metab. 2013;2013:821082. doi:10. 1155/2013/821082.

107. Nair S, Hebbar V, Shen G, Gopalakrishnan A, Khor TO, Yu S, et al. Synergistic effects of a combination of dietary factors sulforaphane and (-) epigallocatechin-3-gallate in HT-29 AP-1 human colon carcinoma cells. Pharm Res. 2008;25(2):387-99. doi:10. 1007/s11095-007-9364-7. The results published in this paper are of importance because it shows the combinatory enhanced effects of two natural products (EGCG and SFN) compared to their respective individual treatment results. In addition, they showed incorporation of a clinical inhibitor of HDACs resulted in greater gene activation. Results such as this further provide evidence that natural products utilized in prevention regimes could provide additive benefit to standard therapies.

108. Amin ARMR, Kucuk O, Khuri FR, Shin DM. Perspectives for cancer prevention with natural compounds. J Clin Oncol. 2009;27(19414669):2712-25. 
109. Carocho M, Ferreira IC. A review on antioxidants, prooxidants and related controversy: natural and synthetic compounds, screening and analysis methodologies and future perspectives. Food Chem Toxicol. 2013;51:15-25. doi:10.1016/j.fct.2012.09.021.

110. Martin SL, Hardy TM, Tollefsbol TO. Medicinal chemistry of the epigenetic diet and caloric restriction. Curr Med Chem. 2013;20(32):4050-9.

111. Patterson SL, Colbert Maresso K, Hawk E. Cancer chemoprevention: successes and failures. Clin Chem. 2013;59(1):94-101. doi: 10.1373/clinchem.2012.185389.

112. Sarkar FH, Li Y, Wang Z, Kong D. Cellular signaling perturbation by natural products. Cell Signal. 2009;21(19298854):1541-7.

113. Surh Y-J. Cancer chemoprevention with dietary phytochemicals. Nat Rev Cancer. 2003;3(14570043):768-80.

114. Green CJ, de Dauwe P, Boyle T, Tabatabaei SM, Fritschi L, Heyworth JS. Tea, coffee, and milk consumption and colorectal cancer risk. J Epidemiol. 2014;24(2):146-53.

115. Wang ZH, Gao QY, Fang JY. Green tea and incidence of colorectal cancer: evidence from prospective cohort studies. Nutr Cancer. 2012;64(8):1143-52. doi:10.1080/01635581.2012.718031.

116. Nechuta S, Shu XO, Li HL, Yang G, Ji BT, Xiang YB, et al. Prospective cohort study of tea consumption and risk of digestive system cancers: results from the Shanghai Women's Health Study. Am J Clin Nutr. 2012;96(5):1056-63. doi:10.3945/ajcn.111. 031419.

117. Wang XJ, Zeng XT, Duan XL, Zeng HC, Shen R, Zhou P. Association between green tea and colorectal cancer risk: a meta-analysis of 13 case-control studies. Asian Pac J Cancer Prev. 2012;13(7):3123-7.

118. Yang G, Zheng W, Xiang YB, Gao J, Li HL, Zhang X, et al. Green tea consumption and colorectal cancer risk: a report from the Shanghai Men's Health Study. Carcinogenesis. 2011;32(11): 1684-8. doi:10.1093/carcin/bgr186.

119. Suzuki E, Yorifuji T, Takao S, Komatsu H, Sugiyama M, Ohta T, et al. Green tea consumption and mortality among Japanese elderly people: the prospective Shizuoka elderly cohort. Ann
Epidemiol. 2009;19(10):732-9. doi:10.1016/j.annepidem.2009. 06.003 .

120. Boehm K, Borrelli F, Ernst E, Habacher G, Hung SK, Milazzo S, et al. Green tea (Camellia sinensis) for the prevention of cancer. Cochrane Database Syst Rev. 2009;3, CD005004. doi:10.1002/ 14651858.CD005004.pub2.

121. Sun CL, Yuan JM, Koh WP, Lee HP, Yu MC. Green tea and black tea consumption in relation to colorectal cancer risk: the Singapore Chinese Health Study. Carcinogenesis. 2007;28(10):2143-8. doi: 10.1093/carcin/bgm171.

122. Yang G, Shu XO, Li H, Chow WH, Ji BT, Zhang X, et al. Prospective cohort study of green tea consumption and colorectal cancer risk in women. Cancer Epidemiol Biomarkers Prev. 2007;16(6):1219-23. doi:10.1158/1055-9965.EPI-07-0097.

123. Sun CL, Yuan JM, Koh WP, Yu MC. Green tea, black tea and colorectal cancer risk: a meta-analysis of epidemiologic studies. Carcinogenesis. 2006;27(7):1301-9. doi:10.1093/carcin/bg1024.

124. Arab L, Il'yasova D. The epidemiology of tea consumption and colorectal cancer incidence. J Nutr. 2003;133(10):3310S-8S.

125. Grandhi BK, Thakkar A, Wang J, Prabhu S. A novel combinatorial nanotechnology-based oral chemopreventive regimen demonstrates significant suppression of pancreatic cancer neoplastic lesions. Cancer Prev Res (Phila). 2013;6(10):1015-25. doi:10.1158/ 1940-6207.CAPR-13-0172.

126. Ajazuddin A, Alexander A, Qureshi A, Kumari L, Vaishnav P, Sharma M, et al. Role of herbal bioactives as a potential bioavailability enhancer for Active Pharmaceutical Ingredients. Fitoterapia. 2014;97:1-14. doi:10.1016/j.fitote.2014.05.005.

127. Sanchez-Bridge B, Leveques A, Li H, Bertschy E, Patin A, ActisGoretta L. Modulation of (-)-epicatechin metabolism by coadministration with other polyphenols in Caco-2 cell model. Drug Metab Dispos. 2015;43(1):9-16. doi:10.1124/dmd.114.060590.

128. Lambert JD, Kwon SJ, Ju J, Bose M, Lee MJ, Hong J, et al. Effect of genistein on the bioavailability and intestinal cancer chemopreventive activity of (-)-epigallocatechin-3-gallate. Carcinogenesis. 2008;29(10):2019-24. doi:10.1093/carcin/bgn182. 